\title{
Jornalismo e novas tecnologias da informação: do digital ao dialógico
}

\author{
Lygia Maria Silva Rocha
}

SANDANO, C.

Para além do código digital:

o lugar do Jornalismo em

um mundo interconectado.

São Carlos: EdUFSCar,

190 p., 2015.

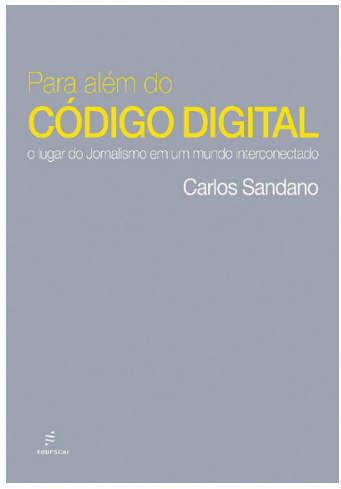

Resumo: Em Para além do código digital, Carlos Sandano analisa a prática jornalística com base nas transformações provocadas pelas novas tecnologias da informação. Para isso, o autor efetua uma atualização de conceitos como a neutralidade, a objetividade e a autonomia, tendo como base tanto a filosofia da ciência como a teoria do jornalismo e apoiando-se em estudos de casos empíricos. O objetivo é verificar quais os valores (cognitivos, epistemológicos e sociais) estão vinculados ao jornalismo e como esses valores são trabalhados na contemporaneidade. Como parte do mundo digital, interconectado e globalizado, o jornalismo ainda teria um papel social e cognitivo a cumprir, principalmente como articulador de vozes e de visões de mundo distintas, como uma forma de produção de conhecimento que visa o endossamento do espaço público democrático.

Palavras-chave: teoria do jornalismo; epistemologia; objetividade; dialogia; tecnologia da informação.

Abstract: Journalism and new information technologies: from digital to dialogical - In Para além do código digital, Carlos Sandano analyzes the journalistic practice from the transformations provoked by the new information technologies. For this, the author performs an update on 
concepts such as neutrality, objectivity and autonomy, based on the philosophy of science and the theory of journalism, supported by empirical case studies. The objective is to verify which values (cognitive, epistemological and social) are linked to journalism and how these values work in the contemporaneity. As part of the digital, interconnected and globalized world, journalism would still have a social and cognitive role to fulfill, mainly as an articulator of distinct voices and worldviews, as a form for the production of knowledge that aims the endorsement of a democratic public space.

Keywords: theory of journalism; epistemology; objectivity; dialogism; information technology.

O que significa ser jornalista no século XXI? Por meio do questionamento, Carlos Sandano, que é professor do curso de Jornalismo da Universidade Mackenzie, em São Paulo, efetua, no livro Para além do código digital, uma atualização de conceitos caros à teoria do jornalismo, como a objetividade e a neutralidade, à luz das novas tecnologias da informação. Porém, o autor não se restringe à análise desses conceitos: trata-se, na verdade, da reflexão sobre uma série de valores vinculados ao jornalismo com o objetivo de pensar a significação dessa atividade na contemporaneidade. Valores como a autonomia e a responsabilidade, valores epistemológicos e valores sociais... Como esses valores podem ser trabalhados em um mundo embebido em produção e em consumo de informação por meio de uma rede digital que funciona em tempo real? Qual o papel do jornalista nesse mundo carregado de signos e no qual os limites entre produtores e consumidores de informação ficam turvos? Como lidar com os embates entre culturas diversas em um ambiente globalizado?

Sandano vai atrás desses valores, mas, desde a Introdução, deixa claro que não se trata de propor uma nova deontologia do jornalismo. Na verdade, o autor recusa a visão estritamente deontológica, no sentido de uma diretriz normativa, pragmática e técnica, já que esta limitaria a pluralidade inerente ao dialogismo, aspecto fundamental do trabalho jornalístico. Ou seja, Sandano pensa valores para o Jornalismo sem trabalhar com universais e sem abdicar dos valores que definem a prática, atualizando-os. Trata-se de "uma busca epistemológica sobre o que seria uma prática virtuosa do jornalismo, discutindo o que são essas virtudes e como estas são entendidas desde diferentes estratégias" (SANDANO, p. 18). Virtudes e estratégias que têm impacto direto na realidade, na formação e no fortalecimento do espaço público democrático. O jornalismo, assim, é pensado como uma forma de conhecimento e como um articulador de um campo dialógico.

No capítulo 2, o autor trabalha a diferença entre deontologia e epistemologia com base no conceito de autonomia na ciência: o cientista precisa de autonomia em relação a constrangimentos externos para o pleno exercício da pesquisa, constrangimentos como, por exemplo, crenças religiosas e ideológicas, restrições estatais etc. O cientista precisa da autonomia para alcançar seus resultados e a sociedade precisa que a ciência seja autônoma para se beneficiar das pesquisas científicas. Da mesma forma, a autonomia 
também é um valor para a prática jornalística: tanto um valor cognitivo (compartilhado epistemologicamente por um grupo profissional) como um valor social para a democracia (ou seja, afeta outros grupos sociais).

Segundo Sandano, a deontologia restringe a autonomia, subordinando a prática jornalística ao estado, ao código civil ou aos regimentos internos das redações. A normatividade reduz os valores a universais que não se verificam como tais, dadas as diferenças entre práticas jornalísticas em diferentes países (o autor cita a diferença entre a "precisão norte-americana" e a "agressividade inglesa" no caso do escândalo envolvendo o News of the World, mostrando discursos de jornalistas favoráveis e desfavoráveis a ambas as práticas), em um mesmo país (com diferentes jornais que estabelecem graus diferenciados de autonomia, com relação, por exemplo, a determinadas posições ideológicas, partidos políticos etc.) e até em um mesmo veículo (ao mostrar que a censura imposta pelo poder autoritário do estado pode ser comparada ao processo de restrição que os próprios jornalistas impõem aos seus companheiros de trabalho por meio de uma hierarquia rígida nas redações).

A vantagem da abordagem epistêmica "é reconhecer os limites da autonomia, possibilitando trabalhar de modo dialógico seus valores intrínsecos (cognitivos) com valores externos (sociais, culturais, morais)" (SANDANO, p. 57). Assim, a deontologia se baseia em um "deve-ser", enquanto a epistemologia se abre para o "ser", para "o que-poderiaser", articulando valores sociais e cognitivos. Passa-se, assim, de um paradigma normativo autoritário para a complexidade das relações intersubjetivas. O jornalista deixa, assim, de ser visto como um mero técnico que executa normas para assumir a responsabilidade como mediador discursivo, como articulador de um campo dialógico e polissêmico.

No capítulo 3, Sandano parte do conceito de relativismo na filosofia da ciência, especialmente em Feyerabend, para, então, analisar os conceitos de objetividade e neutralidade. O relativismo não seria uma exigência metodológica, mas uma postura de abertura dialógica para o outro. Não significa que todas as perspectivas são igualmente válidas, mas implica a importância de se considerar a pluralidade de visões de mundo. Não se nega, assim, a possibilidade de um conhecimento objetivo, mas ressalta-se que a objetividade está inserida em um sistema complexo de múltiplas diferenças. O autor também lança mão da perspectiva construtivista, no sentido de reconhecer que o conhecimento da realidade é uma forma de intervir na transformação da própria realidade. A crítica à objetividade não se trata, portanto, de uma crítica à objetividade como valor cognitivo no jornalismo. Esse valor continua a ser importante. O problema é considerá-lo isoladamente, distanciado de outros valores, como os sociais, por exemplo.

Sandano efetua a articulação da objetividade com o conceito de empatia, entendida, resumidamente, como abertura subjetiva a valores exógenos, como uma capacidade dialógica de aprendizagem com o diferente, de interação com culturas e visões de mundo distintas da nossa. Assim, partindo de uma ideia de objetividade distante do sentido de 
uma ação livre de juízos de valor, e articulando essa ideia com o conceito de empatia, o autor propõe o conceito de "neutralidade inclusiva". Haveria uma "neutralidade restritiva", baseada em uma ideia positivista de objetividade científica, que significa ausência de juízos de valor, e, contrapondo-se a ela, uma "neutralidade inclusiva", baseada no relativismo e na relação entre objetividade e empatia, que remete à inclusão da maior variedade possível de vozes (polifonia) e de sentidos (polissemia). Com base em uma "neutralidade inclusiva", a prática jornalística passa a funcionar em um regime de interação não mais de sujeito-objeto, mas de sujeito-sujeito, e "o jornalismo deixa assim de ser entendido como o relato objetivo da verdade e passa a articular objetivamente as perspectivas subjetivas" (Sandano, p. 91). Articulando objetividade e empatia, passa-se, assim, de uma neutralidade negativa (ausência de juízos de valor) para uma neutralidade positiva (maior inclusão de vozes e sentidos distintos).

O autor analisa, como exemplo, a cobertura jornalística e os debates sobre a relação conflituosa entre Ocidente e Oriente com base nas manifestações a respeito da divulgação do vídeo Innocence os muslims e das charges satíricas representando Maomé, do semanário francês Charlie Hebdo. Verifica-se, assim, como o jornalismo atua em situações de conflitos comunicacionais. O autor dividiu o corpus de análise em quatro grupos, em um movimento que vai do maior fechamento para a maior inclusão possível de perspectivas. Temos, assim, o grupo da "Restrição dogmática" (incompreensão deliberada e fechamento total a outras perspectivas, na qual a possibilidade de comunicação dialógica é mínima); da "Restrição objetiva" (submete o entendimento às normas técnicas em uma abordagem descontextualizada descritiva, na qual as contradições da realidade social são resolvidas colocando-se duas opiniões dicotômicas lado a lado); da "Restrição subjetiva" (abordagem descontextualizada interpretativa que reduz a complexidade a uma perspectiva unidimensional); e, por fim, da "Restrição autoral e tolerante" (a abertura dialógica significando uma visão crítica dos próprios paradigmas).

Porém, é preciso ressaltar que, ao fazer essa diferenciação, Sandano não pretende uma normatização técnica da prática jornalística. A "restrição autoral e tolerante" não seria a melhor e a única forma de retratar a realidade, seria aquela que fornece uma resposta melhor para a comunicação entre diferentes visões de mundo, comunicação esta que se verifica de forma intensa e constante no ambiente globalizado e no mundo das redes digitais. "A narrativa jornalística não se formaria pelo consenso, mas sim pela articulação coerente das controvérsias e das contradições presentes no fato (dado empírico)" (SANDANO, p. 121).

No último capítulo, o autor efetua uma análise extensa sobre as diferentes visões a respeito das novas tecnologias, da internet e do código digital. Verifica a presença de um embate entre "apocalípticos" e "integrados", entre visões pessimistas e otimistas a respeito das transformações sociais e políticas advindas com as novas tecnologias da informação, entre visões críticas e técnicas da comunicação no contexto das redes. 
Com base em análise teórica e em exemplos empíricos como o Wikileaks e a Mídia Ninja, o autor verifica os potenciais das novas redes no sentido de ampliar a informação e a exposição de diferentes visões de mundo. Verifica também que o jornalismo tradicional, com seu esquema unidirecional (com uma fonte produtora e uma massa de consumidores) vê-se ameaçado e em vias de transformação, dado que todo consumidor pode ser também tanto um produtor como um crítico da produção jornalística (caso da Mídia Ninja). Porém, a noção de "neutralidade inclusiva" não significa seguir diretrizes ideológicas (sejam de esquerda ou de direita), mas sim a construção de um espaço dialógico de conversação. O que ocorre nas redes digitais de informação, porém, é uma restrição da universalidade do conteúdo, que acaba se dirigindo de forma restrita para intragrupos que possuem as mesmas ideias, opiniões e visões de mundo, as chamadas "bolhas" de informação. Acaba-se mantendo, de certa forma, aquela lógica dicotômica, fazendo com que nossos preconceitos não sejam desafiados, mas estimulados. Atuar com foco na diversidade é diferente de compartimentalizar milhões de usuários em grupos fechados que não conversam entre si, onde cada grupo não se abre empaticamente ao outro. Assim, a especificidade epistemológica do jornalismo na contemporaneidade seria aquela vinculada à imagem do mediador discursivo, daquele que promove o diálogo intersubjetivo por meio de diferentes estratégias (cognitivas, editoriais, textuais etc.), resultando não apenas na troca de conhecimento, mas na transformação do conhecimento e, também, dos sujeitos envolvidos. As redes sociais e as novas tecnologias não "mataram" o jornalismo, mas trouxeram novos desafios e, a partir deles, reposicionaram essa prática, cujo propósito, mais do que nunca, é colocar o diferente em dialogia e abrir espaços de conversação, visando a construção de uma esfera pública democrática.

Lygia Maria Rocha é doutoranda em Comunicação e Semiótica pela PUC-SP, mestre em Jornalismo pela UFSC e especialista em Comunicação Jornalística - Jornalismo Cultural pela PUC-SP.

lymariarocha@gmail.com 